\title{
ANALYZING KNOWLEDGE, ATTITUDES AND PRACTICES AROUND REUSABLE WATER BOTTLES
}

\author{
Amamchi Amadi ${ }^{1}$, Dale Chen ${ }^{2}$, Esther Tong ${ }^{3}$ \\ 1 Lead Author, B. Tech Student, School of Health Sciences, British Columbia Institute of Technology, 3700 Willingdon Ave, Burnaby, BC V5G \\ $3 \mathrm{H} 2$ \\ 2 Supervisor, School of Health Sciences, British Columbia Institute of Technology, 3700 Willingdon Ave, Burnaby, BC V5G 3H2 \\ 3 Contributor, British Columbia Center for Disease Control, 655 W 12th Ave, Vancouver, BC V5Z 4R4.
}

\begin{abstract}
Background: It has been acknowledged that personal reusable water bottles pose hazards, such as disease-causing organisms, associated with poor water bottle hygiene practices. Currently, there are no recommended frequencies or procedures, or guidelines for personal water bottle cleaning and sanitation. Likewise, there is little information on outbreaks or cases of illness arising from poor personal water bottle hygiene. This may be due to lack of awareness and non-reporting of cases. Therefore, the importance of knowledge, attitudes and practices around reusable water bottles cannot be over emphasized. This research study will ascertain if water bottle hygiene practices among post-secondary education students are adequate to avoid consumption of drinking water with growth of multiple pathogenic microbes like Escherichia coli, Salmonella species, Pseudomonas species, Vibrio cholera and viruses.
\end{abstract}

Method: 83 participants were surveyed using an in person administered survey method. The survey was conducted on British Columbia Institute of Technology (BCIT) student sample using the Survey Monkey platform and was delivered in person via an iPad at a survey stand. Chi-square tests were used to analyze the survey data using NCSS version 12 statistical package. Tables and bar charts were used to explain and give interpretation to $\mathrm{p}$-values from the chi-square tests.

Results: There were found to be no associations between knowledge level around reusable water bottles and either gender or hygiene practices. However, the survey data did show an association between gender and hygiene level. The female participants were more likely to clean their water bottles more frequently than the male participants.

Conclusion: Based on the findings of this study, a health promotion initiative targeted toward male students is recommended to achieve behaviour change in cleaning practices with reusable drinking water 
bottles. Moreover, despite the study findings showing a high level of knowledge among participants, this did not translate to better water bottle hygiene practices, as there was no statistical association between knowledge level and hygiene practice. Therefore, more frequent cleaning of reusable water bottles should be encouraged, highlighting the appropriate cleaning agents and method to be used.

Keywords: Reusable water bottle, knowledge attitudes and practices, hygiene, drinking water

\section{INTRODUCTION}

The consumption of water is a basic necessity of life and this is reflected in the widespread use of bottled water at sports arenas, work, school, and other places. However, in recent times disposable plastic water bottles have been perceived to be environmentally unfriendly and a contributor to global warming (5). This led to the campaign of reducing the environmental impact of these disposable bottles by making use of reusable drinking water bottles (5). Reusable water bottles are commonly used in the recent times as they are considered convenient, less expensive and socially responsible. However, reusable drinking water bottles may be a source of illness to users, especially with unsanitary practices like inadequate washing and sanitizing.

Environmental Health Officers (EHOs) and public health professionals are concerned about the health of reusable bottle users. They believe adequate cleaning and sanitizing of these bottles will prevent users from getting sick from their own bottles (15). Currently, there are no guidelines recommended for personal water bottle cleaning frequency and sanitation. Therefore, understanding exactly what reusable bottle users know about proper hygiene practices (knowledge), how they feel about it (attitudes) and how they actually behave (practices) will help health professionals develop educational and health promotion tools. This information can be used to create awareness and educate the public on the importance of maintaining proper hygiene practices around these reusable water bottles.

\section{LITERATURE REVIEW}

\section{Background}

Reusable drinking water bottles are consistently humid and are easily contaminated via the user's hands and mouth, which are not devoid of microorganisms, especially the normal microbial flora of the skin and mouth. This provides a perfect medium for bacteria survival and multiplication, especially as these drinking water bottles are held at room temperature $\left(21^{\circ} \mathrm{C}\right)$ for long periods of time (1). This should be considered in light of the basic knowledge that time and temperature abuse, crosscontamination, and food handler hygiene are among the top five risk factors that cause foodborne illness (1). Microorganisms will grow without sanitary measures such as washing with 
soap and water and sanitizing with an approved anti-microbial agent. The microorganisms build up in drinking water bottles, which results in biofilm formation (1). Biofilms can inhibit the anti-microbial action of sanitizing agents by shielding and protecting these microbes from destruction. Efforts in trying to sanitize drinking water bottles with biofilm formation may be fruitless in killing these pathogens, as the biofilm provides a shield to these microbes (16). The Food Retail and Food Service Code clearly states the necessity of properly cleaning and sanitizing food contact surfaces (2). Regular washing of reusable drinking water bottles with soap and water is essential as this reduces microbial load up to $70 \%$ and enhances sanitizing agents' ability to get rid of resilient pathogens (2).

\section{Outbreaks from Drinking Water}

It is acknowledged that water can be a source of disease outbreaks (11). Though worldwide efforts have been made through the use of modern technology to ensure safe drinking water is provided, transmission of waterborne diseases is still a matter of major concern (18). Some common foodborne pathogens have also been identified to be associated with water, including Campylobacter, E. coli O157:H7, Salmonella, and Vibrio cholerae, to mention a few (4). These can lead to severe illnesses and death. One example of an outbreak from contaminated drinking water sources is the Walkerton, Ontario E. coli outbreak, which killed 7 people, left 2300 ill and many others with lifelong disabilities. Canadian drinking water safety has improved greatly since the Walkerton incident in 2010. The majority of Canadian provinces have adopted more stringent drinking water guidelines to ensure the availability of safe drinking water for their residents (9).

The Centers for Disease Control and Prevention (CDC) has stated that outbreaks from bottled water are not usually reported but do occur (3). Some of the points of contamination identified were the at the water source, during commercial bottling, shipping, hauling or storage, or at the point of use. In other cases, the point of contamination was unknown. The most recent reported outbreak occurred in 2010, resulting in gastrointestinal illness and esophagitis caused by an unidentified chemical agent (3). The Public Health Agency of Canada (PHAC) and Health Canada also have some outbreak data which identified the water source and distribution systems as the source of contamination (7). Currently, there are no reports regarding outbreaks or consumers getting sick from their own reusable drinking water bottles as a result of contamination and poor hygiene practices. This may be due to lack of awareness and under reporting of cases.

\section{Hygiene Practices Around Reusable Water}

\section{Bottles}

It is generally believed that inadequate hygiene practices with reusable drinking water bottles 
result in high microbial growth, specifically

bacteria and mold (10). Water bottle

manufacturing companies like Thermos,

Rubbermaid, and Contigo provide instructions

on their manufacturer's information guide on

how to use and care for their products (8). It is

unlikely that water bottle users review and

follow these user guides and limited studies have

been conducted to ascertain the severity of the

risk that seldom washed and sanitized bottles

pose to users (10).

Some studies have been identified to assess user behaviour and the microbiological quality of water contained in reusable drinking water bottles. A study carried out in 2006 by former

British Columbia Institute of Technology

(BCIT) student Vanessa Ouellette comprised of both a survey and microbiological testing of samples from different plastic reusable water bottles using the Heterotrophic Plate Count (HPC) testing method (15). HPC is a water testing method that measures the overall bacteriological quality of different drinking water sources (17). In her study, Ouellette sampled mainly water from soft or hard plastic reusable water bottles to assess the relationship between water bottle hygiene behaviour of users and microbial presence. The results indicated high correlation between high level of microbial counts and longer intervals between cleaning (15).
A microbiological testing study conducted on different kinds of reusable drinking water bottles in 2007 by Treadmill, indicated a high bacterial load at the mouthpiece of these water bottles. The study further indicated that bottles with smaller mouthpieces were more difficult to clean and contained higher bacterial loads when compared to bottles with wider mouthpieces. The results of this study cannot be confidently used to draw conclusions or make recommendations as the study was not peer reviewed and had a small sample size of 12 , constituting weak support for the results of this study (14).

Another study, conducted by former BCIT student Adbiel Tabaco, compared the microbiological levels of aerobic bacteria isolated from personal stainless water bottles to the "Aerobic Colony Count Recommendations for Environmental Surfaces" in the Food Quality Check Program's Microbiological Recommendations. The results of this study identified that there was no statistically significant association between the cleaning frequencies and microbial levels in stainless steel water bottles (13).

\section{Knowledge, Attitudes and Practices}

To effectively achieve sustainable behaviour change it is important to understand how the public values, perceives and behaves with respect to reusable drinking water bottles. It is for this reason that the knowledge, attitudes and 
practices (KAP) approach is considered useful

for this research. KAP research approaches are used to understand what people know, believe and do in relation to a specific topic (17).

Some studies have revealed the knowledge, attitudes and practices of participants with respect to water sanitation and hygiene. For example, a quantitative survey study, conducted by students of the University of Michigan, summarized and analyzed water bottle user behavior among different groups of students in the university (6). Their study report concluded that there was a lack of education regarding the quality and safety of the university tap water source and supply and students found it inconvenient to clean their water bottles in between uses. The results of their study led to several recommendations including installation of cleaning sinks for water bottles in resident halls for students and incorporation of water bottle education into freshmen and international student orientations (6). Recommendations like these can help improve sanitary and hygiene concerns with reusable water bottles among students.

Both qualitative and quantitative KAP research studies can provide valuable data on how to improve health promotion services and social welfare for the public. It is necessary for policy makers to understand this in order to make sustainable, appropriate and informed decisions, which will be accessible and beneficial to the intended population (17).

\section{MATERIALS AND METHODS}

This research was conducted using an in-person administered survey. The survey was hosted on the BCIT Survey Monkey platform and was delivered in person at BCIT using an iPad at a survey stand. A script was used to ensure that information provided to each participant was consistent. A short cover letter was also provided to allow the participants to gain some knowledge of the study and confidentiality information. A consent form was also provided to each participant to explain the purpose of the study and to reassure them of the confidentiality of the study. Each participant was also given an opportunity to receive results of the study. BCIT stationary such as pens and customised BCIT lapel pins were made available for interested participants at the survey stand.

\section{RESULTS}

Descriptive Statistics

A total number of 83 reusable bottle users participated in the survey that fit the inclusion criteria. In the survey, the gender identity, age group, and education level were requested from the participants to determine the demographics of the study as seen in Table 1 below. 
Table 1. Summary of Demographics

\begin{tabular}{|c|c|c|c|c|c|c|c|}
\hline \multicolumn{2}{|c|}{ Gender Identity (\%) } & \multicolumn{4}{|c|}{ A ge Group (\%) } & \multicolumn{2}{|c|}{ Education Level (\%) } \\
\hline Male & 48.78 & 18-28 years & 93.90 & $\begin{array}{l}49-58 \\
\text { years }\end{array}$ & 0.00 & $\begin{array}{l}\text { High } \\
\text { School }\end{array}$ & 39.02 \\
\hline Female & 51.22 & $29-38$ years & 4.88 & $59+$ years & 0.00 & College & 3293 \\
\hline Other & 0.00 & \multirow[t]{2}{*}{$39-48$ years } & \multirow[t]{2}{*}{122} & \multirow{2}{*}{$\begin{array}{l}\text { Prefer not } \\
\text { to answer }\end{array}$} & \multirow[t]{2}{*}{122} & University & 20.73 \\
\hline $\begin{array}{l}\text { Prefer not } \\
\text { to answer }\end{array}$ & 122 & & & & & Grduate & 854 \\
\hline
\end{tabular}

The participants were then asked questions that focused on water bottle age and use, which are summarized in Table 2.

Table 2. Summary of water bottle age and frequency of use

\begin{tabular}{|c|c|c|c|c|c|}
\hline \multicolumn{2}{|c|}{ Water Bottle Age (\%) } & \multicolumn{4}{|c|}{ Frequency of Use (\%) } \\
\hline Days & 10.97 & Daily & 90.12 & Monthly & 1.23 \\
\hline Weeks & 8.54 & Weekly & 3,70 & Never & 2.47 \\
\hline Months & 40.24 & \multirow[t]{3}{*}{ Bi-Weekly } & \multirow[t]{3}{*}{1.23} & \multirow{3}{*}{$\begin{array}{l}\text { Prefer not } \\
\text { to answer }\end{array}$} & \multirow[t]{3}{*}{2.47} \\
\hline Years & 35.37 & & & & \\
\hline $\begin{array}{l}\text { Prefer not } \\
\text { to answer }\end{array}$ & 6.10 & & & & \\
\hline
\end{tabular}

The cleaning methods and frequencies are summarized in Table 3:

Table 3. Summary of cleaning Methods and Frequency

\begin{tabular}{|c|c|c|c|c|c|}
\hline \multicolumn{2}{|c|}{ Cleaning Method (\%) } & \multicolumn{4}{|c|}{ Cleaning Fr equency (\%) } \\
\hline $\begin{array}{l}\text { Wamn Water } \\
\text { Rinse }\end{array}$ & 24.05 & Daily & 47.56 & Monthly & 4.88 \\
\hline $\begin{array}{l}\text { Wash with Soap } \\
\text { and Water }\end{array}$ & 64.63 & Weekly & 32.93 & Never & 6.10 \\
\hline $\begin{array}{l}\text { Wash, rinse and } \\
\text { sanitize }\end{array}$ & 3.66 & Bi Weekly & 9.76 & $\begin{array}{l}\text { Prefer not } \\
\text { to answer }\end{array}$ & 2.44 \\
\hline $\begin{array}{l}\text { Prefer not to } \\
\text { answer }\end{array}$ & 4.88 & & & & \\
\hline
\end{tabular}

The relationships between gender and knowledge level, gender and practices and knowledge level and practices are summarised in bar graphs shown in figures 1,2 and 3, respectively.

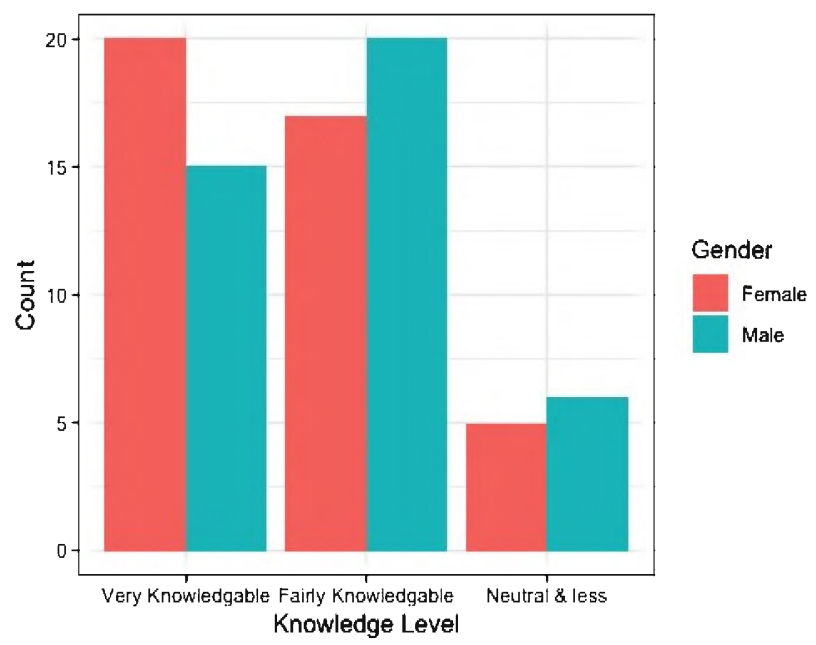

Figure 1: Gender Vs. Knowledge Level 


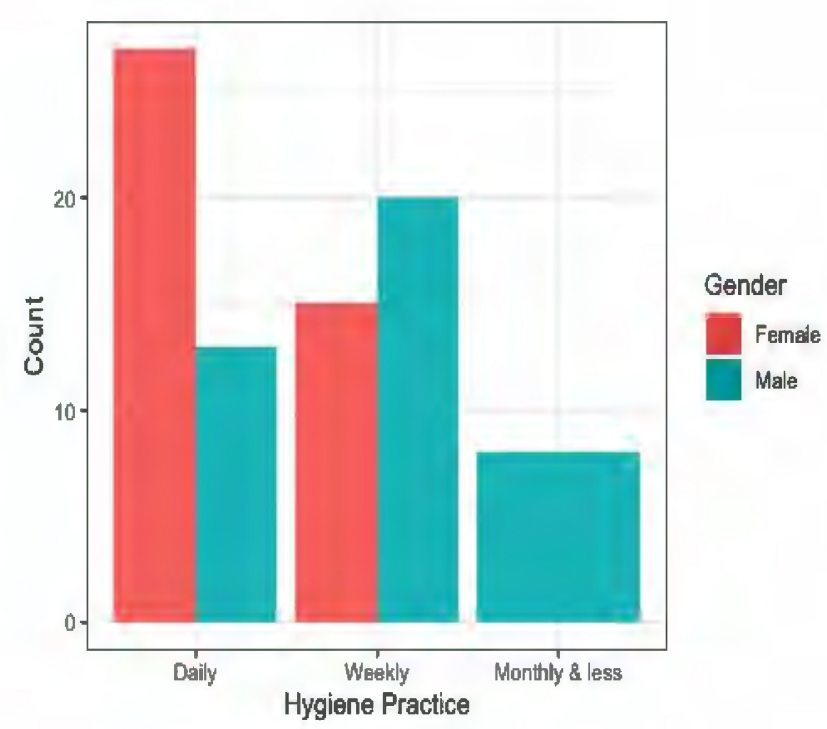

Figure 2: Gender Vs. Hygiene Practices

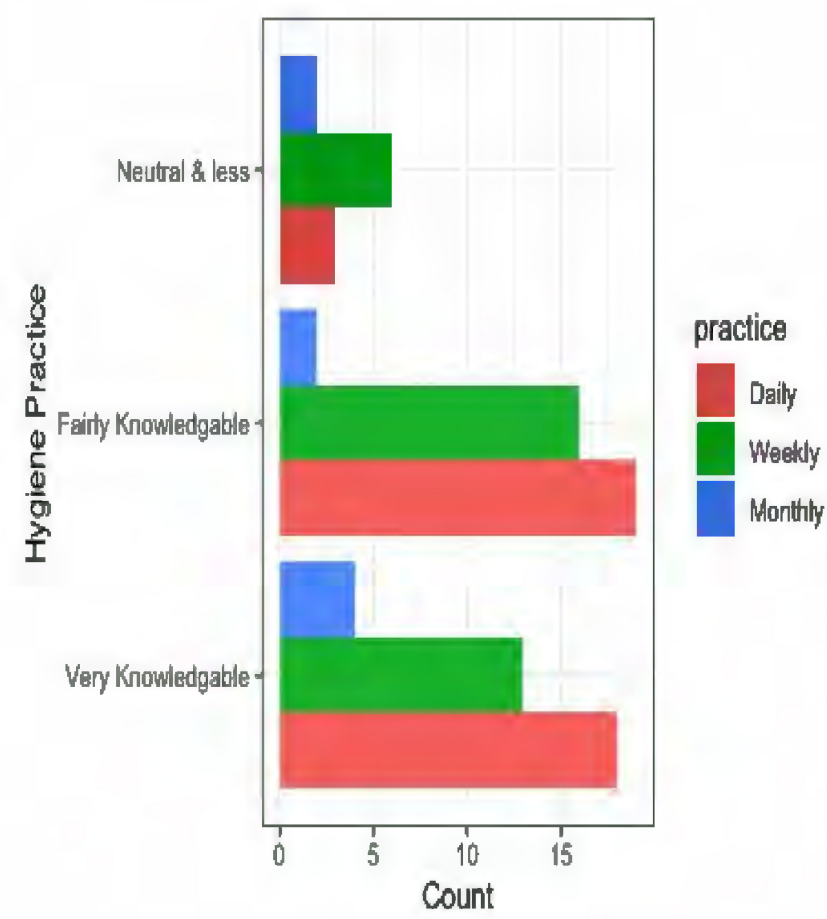

Figure 3: Knowledge Level Vs. Hygiene Practices

\section{Inferential Statistics}

The survey results showed no statistically significant association between gender and knowledge level around reusable water bottles. The data also indicated no association between knowledge levels and hygiene practices.

However, the data did indicate that there is an association between gender and hygiene level around reusable water bottles, with female students cleaning their water bottles more often than male students.

\section{DISCUSSION}

Results from the survey reveal that there is no association between gender and knowledge level around reusable water bottles as there was no statistical significance, based on the Chi-Square Test. Providing participants with a knowledge based question regarding the importance of regular cleaning of reusable water bottles and how strongly they believe that they can get sick from their own reusable water bottles, resulted in a performance that was equivalent in magnitude for both male and female respondents. The female respondents appeared very knowledgeable while their male counterparts appeared to be fairly knowledgeable.

The knowledge-based questions and hypothesis testing agreed with the findings demonstrated in Ouellette's study and Ryan et al.'s study (15 \& 19). Both of these studies revealed that inadequate cleaning practices contribute to high microbial load on reusable water bottles. Interestingly, the majority of the survey respondents both male and female were either 
very or fairly knowledgeable, affirming to the fact that they were aware that irregular cleaning of their reusable water bottles could lead to high microbial load, which could make them sick.

The Chi-Square test further revealed that there is an association between gender and hygiene practices around reusable water bottles. The female students tend to clean their water bottles more often that the male students. As seen in the descriptive results (Figure 2), more than half of the female respondents ( 27 respondents) clean their water bottles daily while few of the male respondents (13 respondents) clean their bottles daily. On the other hand, 8 male respondents clean their bottles monthly or less, while none of the female respondents were found in this category. The hypothesis testing result was found to be interesting as it supports the general notion that young female adults are generally more hygiene conscious than young male adults. This is also in line with sanitation and hygiene study, were young male adults failed to wash their hands after using the washroom compared to their female counterparts (12).

The third Chi-Square hypothesis testing revealed that there is no association between knowledge level and hygiene practice around reusable water bottles. The results from this hypothesis testing basically signify that the behaviour and hygiene practices of participants in the study were not impacted by their high knowledge level. This is in agreement with the findings of the 2011
University of Michigan study, which concluded that students found it inconvenient to clean their water bottles in between uses (6). This is also seen in the inadequate hygiene practice level revealed in the current study.

\section{LIMITATIONS}

One of the major limitations to this study was time constraint. Limited time was allocated to surveying participants and analyzing their responses for this project. This impacted the sample size for this study, especially as inperson surveys are typically more time consuming and can result in lower response rates. Another limitation to this study was financial constraint. A very small financial budget was allocated for this study, which resulted in only collecting responses from BCIT students. Both the time and financial constraints had detrimental impacts on the sample size for this study. Though the researcher managed to ascertain a reasonable sample size, a larger sample size would have enhanced a more robust statistical analysis of the survey responses, and also enabled the researcher to survey other postsecondary students outside BCIT.

Additionally, the use of an in-person administered survey was also a limitation as these studies have the disadvantage of low response rates from participants. This increased the stress for the researcher in getting responses from participants, as students were mostly 
running late for their lectures or lab sessions and did not have time to complete the survey.

To improve the validity of this study and also increase the response rate from participants, it is recommended that a different survey approach be used. For example, sending the survey online to different BCIT groups would have been less stressful and less time consuming compared to the in-person approach used in this study.

Additionally, the online survey approach will facilitate surveying other post-secondary institutions as mentioned above, as the researcher would not have to travel to these institutions to survey students. This approach would increase the sample size, enable a more robust statistical analysis and further make the study findings more generalizable.

\section{KNOWLEDGE TRANSLATION}

The findings of this study revealed that the members of the BCIT community require improvements in reusable bottle hygiene practices as their high knowledge level regarding the importance of regular water bottle cleaning did not impact their hygiene practice level, especially among the male population. Since enforcing cleaning policies concerning reusable water bottles is not guaranteed as there are no legislation/guidelines to facilitate enforcement, it should be recommended that posters be placed at water bottle refill stations around campus and residences as reminders. Information on the importance of regular cleaning of reusable water bottles should be included in the poster with the preferred cleaning methods to get rid of pathogenic microbes. For example, cleaning with warm and soapy water with a cleaning brush could be recommended (13). This will basically serve as a health promotion initiative to achieve behaviour change around reusable water bottle hygiene practices.

This could also be done at other post-secondary institutions in British Columbia, like the Simon Fraser University and University of British Columbia facilities, with the support and guidance of all appropriate school governing bodies. Additionally, it is recommended that washing sinks be installed and equipped with the appropriate cleaning agents and materials like soap and brushes at water bottle refill stations around theses campuses and residences. This will encourage cleaning behavior before water bottle refill and use (6).

\section{FURTHER RESEARCH}

As this research study covered mainly KAP aspects, this researcher recommends:

- Surveying a larger population outside of BCIT community. This would include surveying different municipalities, going to gyms, restaurants, community centers, schools, etc.

- Sample one water bottle over different cleaning frequencies using a consistent usage pattern and cleaning method. 
- Measure chlorine residual in drinking water supply and analyse its effect on microbial growth and multiplication in reusable water bottles.

\section{CONCLUSIONS}

Based on the findings of this study, female students are more likely to clean their water bottles more frequently than male students. This necessitates a health promotion initiative, having male students as the target audience, to achieve behaviour change. Moreover, despite the study findings showing high knowledge level among participants, this did not impact their hygiene practices. Therefore, more frequent cleaning of reusable water bottles should be encouraged, highlighting the appropriate cleaning agents and method to be used. These behaviour changes will prevent and minimize the risk of potential exposure to harmful pathogens which are capable of growing and multiplying in reusable drinking water bottles, resulting in serious health consequences.

\section{ACKNOWLEDGMENTS}

The author would like to thank Dale Chen, Helen Heacock and Fred Shaw for their guidance and support throughout the study.

\section{COMPETING INTERESTS}

The author declares that they have no competing interests. 


\section{REFERENCES}

1. BC Center for Disease Control., (2010). Food Protection Services. A guide for environmental health [Internet]. Vol. 3, Handbook. P 16. Retrieved from: http://www.bccdc.ca/resourcegallery/Documents/Guidelines and Forms/Guidelines and Manuals/EH/FPS/Food/EnvMonitoring $\underline{\text { HygieneGuideforEHOs.pdf }}$

2. Canadian Food Inspection System, Implementation Group (2004). Food Retail and Food Services Code: 76. Retrieved from: http://foodsafe.ca/resources/Food Servi ces Code2004.pdf

3. Centers for Disease Control and Prevention (CDC) 2014. Commercially Bottled Water $\mid$ Drinking Water $\mid$ Healthy Water | CDC [Internet]. Center of Disease Control and Prevention. Retrieved from: https://www.cdc.gov/healthywater/drink ing/bottled/index.html

4. Centers for Disease Control and Prevention (CDC) 2012. Water-related diseases, contaminants, and injuries by type. Retrieved from:

http://www.cdc.gov/healthywater/diseas e/type.html.

5. Cheney P, Foss K., (2014) Is bottled water really better? The Globe and Mail; Retrieved from:

https://beta.theglobeandmail.com/news/ national/is-bottled-waterreallybetter/article416501 1/?ref=http://w ww.theglobeandmail.com\&https://learn. bcit.ca/d21/le/content/569884/viewConte nt/4069828/View
6. Easley-Appley C, Bergenson Z, Key J, Richards LS, Silver L, Wisselman B., (2011) Understanding Water Bottle Behavior of Students. Retrieved from: http://graham.umich.edu/media/files/ca mpus-coursereports/WaterBottleBehaviorFinalReport .pdf

7. Health Canada (HC) (2009) Bottled Water - Canada.ca. Retrieved from: https://www.canada.ca/en/healthcanada/services/food-nutrition/foodsafety/information-product/bottledwater.html

8. Ignite USA, (2014). Contigo Stainless Steel Water Bottle Care and Use Instructions.

9. Inside Walkerton (2010). Canada's worst-ever E. coli contamination. CBC News. Retrieved from https://www.cbc.ca/news/canada/insidewalkerton-canada-s-worst-ever-e-colicontamination-1.887200.

10. Kuan, W. H., and Y. L. Chen., (2016). Bottle material and cleansing procedures of infant feeding bottles. The Southeast Asian J. Trop.Med. Publ. Health 47:142-151.

11. Maunula, L., I. T. Miettinen, and C. H. Von Bonsdorff., (2005). Norovirus outbreaks from drinking water. Emerg. Infect. Dis. 11:1716-1721

12. Sibiya, J., \& Gumbo, J. (2013). Knowledge, Attitude and Practices (KAP) Survey on Water, Sanitation and Hygiene in Selected Schools in Vhembe District, Limpopo, South Africa. International Journal of Environmental Research and Public Health, 10(6), 2282-2295. doi: 10.3390/ijerph10062282. 
13. Tabaco, A. (2018). Bacterial Growth in Personal Stainless-Steel Water Bottles: How Often Should You Clean Your Bottle? BCIT Environmental Health Journal.

14. Treadmillreview (2017). Water Bottle Germs Revealed. Retrieved from: http://www.treadmillreviews.net/waterbottle-germs-revealed/

15. Ouellette V., (2006). Determining the Relationship Between Drinking water quality of personal water bottles and cleaning practices followed by the public. BCIT Environ Heal.;44.

16. Van Houdt R, Michiels CW., (2010). Biofilm formation and the food industry, a focus on the bacterial outer surface. $J$ Appl Microbiol. 109(4):1117-31.
17. World Health Organization (WHO) 2013. Advocacy, communication and social mobilization of TB control: A guide to developing knowledge, attitude and practice surveys. Retrieved from http://whqlibdoc.who.int/publications/20 08/9789241596176 eng.pdf. Accessed October 20th, 2019.

18. Venter, S. N., (2000). Rapid Microbiological Monitoring Methods: The Status Quo. Intl. Water Assn. Blue Pages. Retrieved from:

http://www.waterfund.go.ke/watersourc e/Downloads/003.\%20Rapid\%20Microb iological $\% 20$ Monitoring\%20Methods.p $\underline{\mathrm{df}}$

19. Ryan MC, Oliphant J.A, Chu A, (2002). Bacterial Water Quality in Elementary Students. Can J Public Heal.;93(5):3667. 